Federal Reserve Bank of Minneapolis

Research Department Staff Report 308

Revised April 2008

\title{
Time Inconsistency and Free-Riding in a Monetary Union*
}

\author{
V. V. Chari \\ University of Minnesota \\ and Federal Reserve Bank of Minneapolis
}

\section{Patrick J. Kehoe}

University of Minnesota, Federal Reserve Bank of Minneapolis, and National Bureau of Economic Research

\begin{abstract}
We analyze the setting of monetary and nonmonetary policies in monetary unions. We show that in these unions a time inconsistency problem in monetary policy leads to a novel type of free-rider problem in the setting of nonmonetary policies, such as labor market policy, fiscal policy, and bank regulation. The free-rider problem leads the union's members to pursue lax nonmonetary policies that induce the monetary authority to generate high inflation. The free-rider problem can be mitigated by imposing constraints on the nonmonetary policies, like unionwide rules on labor market policy, debt constraints on members' fiscal policy, and unionwide regulation of banks. When there is no time inconsistency problem, there is no free-rider problem, and constraints on nonmonetary policies are unnecessary and possibly harmful.
\end{abstract}

${ }^{*}$ The views expressed herein are those of the authors and not necessarily those of the Federal Reserve Bank of Minneapolis or the Federal Reserve System. 
Since the 1990s, interest has grown in the design of monetary unions - groups of political units (countries or states or provinces) that have a great deal of independence in setting fiscal and other nonmonetary policies, but that share a central monetary authority, an independent entity which sets a single monetary policy for all the members of the union. In practice, some monetary unions have worked poorly while others have worked well. Argentina is an example of an unsuccessful one; the United States, a successful one; and the jury is still out on the European Union. Why are some monetary unions successful and others not? Here we develop a theory that answers this question.

The time inconsistency problem in monetary policy is at the heart of our theory. We argue that under some circumstances, this monetary policy problem leads to a novel type of free-rider problem in the setting of nonmonetary policies by union members. Free-riding union members pursue lax nonmonetary policies that benefit themselves individually, but that induce the monetary authority to pursue policies that generate high inflation for the whole union.

One way to eliminate both problems is to directly solve the time inconsistency problem in monetary policy. As is well-known, in theory, at least, this problem can be solved by imposing commitment or reputational mechanisms on the monetary authority. When either type of mechanism is in place, there is no free-rider problem, so that directly solving the time inconsistency problem indirectly solves the free-rider problem too. In practice, of course, it is difficult to change the degree of effective commitment, say, by developing a reputation. For our purposes, we will simply assume as necessary that a monetary authority either has or does not have a time inconsistency problem.

More interestingly, we show that solving a monetary union's free-rider problem helps mitigate its time inconsistency problem in monetary policy. The free-rider problem can be solved by imposing unionwide constraints on nonmonetary policies, such as rules on labor market policies, debt constraints on fiscal policy, and regulation of banks. When union 
members' nonmonetary policy options are limited, the monetary authority is less likely to be induced to act in ways that increase inflation. The constraints thus do not necessarily eliminate the time inconsistency problem, but they do at least reduce it.

We first make these points in a general theoretical setup. Our model has governments that set nonmonetary policies noncooperatively, private agents that behave competitively, and a benevolent monetary authority that chooses the inflation rate. The monetary authority's optimal inflation rate depends on the decisions of private agents and on the individual governments' nonmonetary policies. Private agents make their decisions anticipating the choice of the monetary authority. Governments choose their nonmonetary policies anticipating the choices of both private agents and the monetary authority.

In our setup, the free-rider problem is quite different from that in the existing literature. In the standard formulation of the free-rider problem, decision makers are directly linked; the actions of each decision maker directly affect the payoffs of others. Our setup has no such direct links. Here the nonmonetary policy of each government affects the common inflation rate and thus indirectly affects the payoffs of other governments. This indirect link does not, however, suffice to generate a free-rider problem. We use an envelope argument to prove that.

Here the source of the free-rider problem is, rather, the behavior of forward-looking private agents when the monetary authority cannot commit to a policy. Without such commitment, a change in nonmonetary policy by one of the union's member governments induces the private agents to predict a change in unionwide inflation, and this predicted change induces them to change their decisions. Because each government cares about the decisions of its own private agents, a change in nonmonetary policy by any member government affects the welfare of them all. This indirect link results in a free-rider problem. With commitment by the monetary authority, there is no free rider problem even if the model has forward-looking private agents. 
To highlight the role of private agents in generating the free-rider problem, we start by considering a monetary union without them, that is, with only governments and a monetary authority. We show that in this environment, as long as the monetary authority is benevolent, there is no free-rider problem.

After detailing the theory, with as well as without private agents, we consider applications to three common types of nonmonetary policies: labor market policy, fiscal policy, and bank regulation.

We first apply our theory to labor market policy. To do so, we modify the classic model of time inconsistency in monetary policy (due to Kydland and Prescott 1977 and Barro and Gordon 1983). In our modification of this classic model, governments of countries in a monetary union determine the natural rate of unemployment by their setting of labor market policies. We show that with this setup, the free-rider problem leads governments to adopt policies that result in excessively high unemployment and inflation. Constraints on these labor market policies eliminate the free-rider problem and help mitigate the time inconsistency problem.

We then apply our theory to fiscal policy. We consider a simple dynamic model with many countries united in a monetary union. Each country's fiscal authority finances government spending by issuing nominal debt to its residents. After that, the union's monetary authority decides on the common inflation rate. The monetary authority balances inflation's benefits against its costs. Higher inflation has benefits because it reduces the real value of nominal debt and thus reduces the amount of distortionary taxes that must be raised by each country's government in order to repay the debt. Higher inflation also has costs because it distorts allocations and thus reduces output. In our model, as the debt rises, the benefits of inflation rise more than the costs. Hence, the larger the debt that the monetary authority inherits, the higher it sets the inflation rate.

In deciding on its level of government spending, each country's fiscal authority balances 
the gains from government spending against the costs of future distortions, including the induced costs of higher inflation on its own output - ignoring inflation's costs on the output of other countries. Thus, relative to a cooperative benchmark, each fiscal authority issues too much debt, which leads the monetary authority to create too much inflation, which in turn leads to an inefficiently low level of output for all countries in the union.

In principle, if the monetary authority can somehow effectively commit to its policy, then fiscal authorities have no incentive to issue too much debt, and the union has no freerider problem. In practice, though, such commitment is often not available, and monetary unions have typically chosen to attack the free-rider problem directly. One way of doing so is to impose constraints on the amount of debt that governments of union members can issue. In our example, appropriately chosen constraints solve the free-rider problem.

Finally, we apply our theory to bank regulation. We develop a simple dynamic banking model with many countries united in a monetary union. Each country's government regulates the riskiness of its banks' portfolios. When banks cannot fully pay off depositors, the monetary authority prints money to pay the residual amount, thus increasing inflation. Each country's government thus balances the costs of regulation intended to reduce bank riskiness against the induced costs of inflation resulting from bank bailouts. In doing so, each government ignores the induced inflation costs on other countries in the union. These forces also generate a free-rider problem in which, compared with efficient levels, regulation of banks is lax, bank bailouts are too frequent, and the rate of inflation is excessive. If no mechanism is available to solve the time inconsistency problem directly, then the free-rider problem in this model can be mitigated with mutually agreed upon bank regulation.

Our general analysis and the three applications suggest an answer to our original question, Why are some monetary unions successful and others not? A monetary union is likely to fail when it has a time inconsistency problem in monetary policy and no effective constraints on the nonmonetary policies of its members. 
Consider some examples of actual monetary unions. Argentina has experienced high and volatile inflation rates. Jones, Sanguinetti, and Tommasi (2000), Cooper and Kempf (2001a, b), Tommasi, Saiegh, and Sanguinetti (2001), and Nicolini et al. (2002) have argued that the nonmonetary policies have not been effectively constrained by the central government and that the central bank has routinely bailed out the provincial governments. Argentina seems to be an example of a monetary union which has a serious time inconsistency problem with its monetary policy and which is unable to constrain the nonmonetary policies of its provinces. In this sense, the poor performance of the monetary union in Argentina is consistent with our theory.

The United States has experienced much lower and less volatile inflation rates than many other monetary unions. The independence of the Federal Reserve System apparently reduces the time inconsistency problem in monetary policy and thereby insulates the monetary authority from pressures of state governments. In this sense, the good performance of the monetary union in the United States is also consistent with our theory.

Our theory suggests that the success of the European Monetary Union is not yet assured. The charter of the European Central Bank was explicitly designed to make it independent in order to help it overcome time inconsistency problems. If the central bank is able to overcome these problems the European Monetary Union will be successful. Even if the central bank is not able to overcome these problems, the Union may still be successful if it enforces the constraints on nonmonetary policies in the Maastricht Treaty and the Stability and Growth Pact. The worrisome scenario is that the central bank will not be able to resist pressures to inflate and the Union will be unwilling to enforce its constraints on nonmonetary policies.

In this context, it is worth noting that our theory predicts that when constraints that enforce cooperative outcomes are agreed to by governments ex ante, each government has a strong incentive to violate these constraints ex post. In practice, the European Union has 
experienced significant difficulty in enforcing constraints on the fiscal policies of its member countries. The observation that some member countries desire to violate the terms of the treaty does not, by itself, imply that the treaty was poorly designed. This desire is exactly what our theory predicts would occur with a well-designed treaty.

The behavior of other monetary unions is consistent with our theory as well. Von Hagen and Eichengreen (1996) find that 37 of the 49 countries they study impose restrictions on the fiscal policies of their subcentral governments. Such restrictions are consistent with a concern by central governments that they have not successfully solved the time inconsistency problem in monetary policy.

Our work here generalizes and expands the analysis of our earlier work, Chari and Kehoe (2007). Here we lay out a general framework for analyzing free-rider problems in monetary unions and apply it to three types of nonmonetary policies. Our second applied example here is related to the analysis in the earlier work. There we assume that governments borrow from lenders who live outside the monetary union in order to smooth consumption over time. The union's monetary authority uses inflation as a way to levy a tax on the nominal debt holdings of these outside lenders. Here we assume instead that governments finance their spending by borrowing from their own residents and repay the debt with distorting taxes. The monetary authority uses inflation here as a way to reduce the real value of that debt and, hence, the required tax distortions.

Our work here is also related to a literature on fiscal policy in monetary unions, including the work of Giovannini and Spaventa (1991), Sibert (1992), Dixit and Lambertini (2001), Uhlig (2002), and especially Beetsma and Uhlig (1999) and Cooper and Kempf (2001, 2004). Beetsma and Uhlig, however, focus on a monetary union's ability to discipline political economy problems among its union members, problems our monetary union does not have. Here the free-rider problem arises solely because of a time inconsistency problem. Cooper and Kempf, meanwhile, do focus on a free-rider problem, but not one like ours, that arises from 
time inconsistency. Indeed, Cooper and Kempf emphasize that their free-rider problem disappears when the union's monetary policy is to maximize the welfare of the residents of the union members.

The gains from setting fiscal policy cooperatively across countries have been discussed extensively and are well-understood. Such cooperation has been shown to be desirable if countries' fiscal policies affect world prices and real interest rates (Chari and Kehoe 1990, Canzoneri and Diba 1991). That kind of cooperation, however, is not especially related to countries being in a monetary union. We thus here abstract from the issues it raises by assuming that the policies of the countries joined in a monetary union do not affect world prices and real interest rates.

An extensive literature has discussed the gains from setting fiscal policy cooperatively across countries have been discussed extensively and are well-understood. Such cooperation has been shown to be desirable if countries' fiscal policies affect world prices and real interest rates (Chari and Kehoe 1990, Canzoneri and Diba 1991). That kind of cooperation, however, is not related uniquely to countries being in a monetary union. We thus abstract from the issues it raises by assuming that the policies of the countries joined in a monetary union do not affect world prices and real interest rates.

\section{THEORY}

\subsection{Without Private Agents}

One of our principal contributions is to highlight the subtle source of free-rider problems in environments with benevolent governments and a benevolent monetary authority: the behavior of forward-looking private agents. In order to set the stage for our analysis, we begin with a simple setup without private agents. In this environment, at first glance, there appears to be a free-rider problem, but closer examination reveals that there is none.

Consider a world economy with $N$ countries indexed $i=1, \ldots, N$ united in a monetary union, with one monetary authority that chooses unionwide monetary policy. The govern- 
ment of country $i$ chooses a nonmonetary policy $\tau_{i}$, and the monetary authority of the union chooses a common inflation rate for the union, denoted $\pi$. The payoff (or welfare) from these choices to the government of country $i$ is

$$
V\left(\tau_{i}, \pi\right)
$$

Consider first an environment in which inflation $\pi$ is some arbitrary function of nonmonetary policies: $\pi(\bar{\tau})$, where $\bar{\tau}=\left(\tau_{1}, \ldots, \tau_{N}\right)$. If governments choose their nonmonetary policies simultaneously and noncooperatively, then the first-order condition for nonmonetary policy $\tau_{i}$ in this environment is that

$$
V_{\tau}+V_{\pi} \frac{\partial \pi}{\partial \tau_{i}}=0
$$

Here and throughout $V_{\tau}$ and $V_{\pi}$ denote the derivatives of $V\left(\tau_{i}, \pi\right)$. (This is our standard notation for derivatives.) Here and throughout we also consider cooperative equilibria in which the nonmonetary policies are chosen to maximize the sum of all government payoffs (or all the countries' welfare). We view these cooperative equilibria as benchmarks for welfare that we use to judge the efficiency of the noncooperative equilibria, rather than as a description of how governments make decisions. Here the cooperative nonmonetary policies maximize $\sum_{i=1}^{N} V\left(\tau_{i}, \pi\right)$, so that, imposing symmetry, we see that the first-order condition for nonmonetary policy $\tau_{i}$ is that

$$
V_{\tau}+N V_{\pi} \frac{\partial \pi}{\partial \tau_{i}}=0
$$

The first-order conditions (2) and (3) look just like those we would see in classic free-rider problems. An example is the sharing-the-bill problem, in which $N$ individuals dine at a restaurant, each orders $\tau_{i}$, and they share the bill equally, so that $\pi(\bar{\tau})=\sum_{i=1}^{N} \tau_{i} / N$. Clearly, in this situation, each individual free-rides off the other diners since, at the margin, each individual enjoys all the benefits of extra food but pays only $1 / N$ th of the cost.

This result might seem to suggest that free-riding problems arise in monetary unions from the same sources as in classic problems. Closer examination reveals, however, that there 
is no free-riding in the environment described above, as long as the monetary authority is benevolent.

To see this, assume that the monetary authority is benevolent in that it maximizes the

sum of the payoffs to the governments $\sum_{i=1}^{N} V\left(\tau_{i}, \pi\right)$. Suppose that the monetary authority chooses inflation after each government chooses its nonmonetary policy $\tau_{i}$. Then $\pi(\bar{\tau})$ is no longer arbitrary but is instead defined implicitly by the first-order condition

$$
\sum_{i=1}^{N} V_{\pi}\left(\tau_{i}, \pi\right)=0
$$

In a symmetric equilibrium, (4) implies that $V_{\pi}=0$. Using this result, we see that here there is no free-rider problem because the first-order conditions (2) and (3) coincide. Obviously, this result does not depend on the timing of actions.

Thus, in this environment, with a benevolent monetary authority, a monetary union has no free-riding problem. In practice, of course, monetary unions are plagued with such problems. Their problems arise from a source that is not captured in the simple environment just described - from the behavior of private agents, from which we have abstracted. As we shall see, adding private agents to the environment adds a time inconsistency problem in monetary policy that leads to a free-rider problem in nonmonetary policy.

\subsection{With Private Agents}

We now introduce private agents into the monetary union setup just described. We then make explicit the logic by which a time inconsistency problem in monetary policy leads to a free-rider problem in nonmonetary policy.

Consider extending the setup with just a union of governments and a monetary authority to include in each country a continuum of private agents indexed $j \in[0,1]$, each of whom chooses an action $z_{i j}$. Let $x_{i}=\int z_{i j} d j$ denote the aggregate choice of actions by private agents in country $i$. In this extension, the payoffs to private agents from these choices are

$$
V\left(\tau_{i}, z_{i j}, x_{i}, \pi\right)
$$


where, as before, $\tau_{i}$ denotes nonmonetary policy by the government of country $i$ and $\pi$ denotes the common inflation rate.

The payoff to the government of an individual country $i$ is the integral of the payoffs to the private agents in that country,

$$
\int V\left(\tau_{i}, z_{i j}, x_{i}, \pi\right) d j
$$

whereas the payoff to the union's monetary authority is the sum of the payoffs to all the governments (or the union's welfare):

$$
\sum_{i=1}^{N} \int V\left(\tau_{i}, z_{i j}, x_{i}, \pi\right) d j
$$

Notice that we have assumed that the nonmonetary policies of individual governments do not directly affect the payoffs to other governments; thus, the only way governments in this union interact is through the effect of their actions on the common inflation rate. We make this assumption in order to abstract from standard nonmonetary policy linkages across countries, like tariffs and taxes. Such linkages have been analyzed extensively in the literature and have no obvious bearing on issues concerning a monetary union. (See, for example, the work of Chari and Kehoe 1990.)

Typically, a time inconsistency problem in monetary policy arises when the monetary authority cannot effectively commit to an inflation policy. We will show that without effective commitment in a monetary union, the union has a free-rider problem, which leads noncooperative outcomes to differ from cooperative outcomes. We show that the union has no such problem when the monetary authority can commit.

We formalize the lack of commitment that drives the time inconsistency problem in a monetary union with a no commitment game that has the following timing. First the governments choose $\tau_{i}$, then private agents choose $z_{i j}$, and finally the monetary authority chooses $\pi$. We focus on an equilibrium in which all private agents within a country choose the same actions, so that $z_{i j}=x_{i}$ for all $i$ and $j$. 
A noncooperative equilibrium of this game is given by nonmonetary policies $\bar{\tau}=$ $\left(\tau_{1}, \ldots, \tau_{N}\right)$, private agent decision rules $x_{i}(\bar{\tau})$ that depend on those policies, and a monetary policy function $\pi(\bar{\tau}, \bar{x})$ that depends on both the nonmonetary policies $\bar{\tau}$ and the private agents' decisions $\bar{x}=\left(x_{1}, \ldots, x_{N}\right)$ such that $(i)$ for all $\bar{\tau}, \bar{x}$, the policy $\pi(\tau, \bar{x})$ maximizes the monetary authority's payoff; $(i i)$ for each private agent $i j$, for all $\bar{\tau}, x_{i}(\bar{\tau})$ solves

$$
\max _{z_{i j}} V\left(\tau_{i}, z_{i j}, x_{i}(\bar{\tau}), \pi(\bar{\tau}, \bar{x}(\bar{\tau}))\right)
$$

where $\bar{x}(\bar{\tau})=\left(x_{1}(\bar{\tau}), \ldots, x_{N}(\bar{\tau})\right) ;(i i i)$ for each government $i$, given the nonmonetary policies of the other governments $i^{\prime}$, the private agents' decision rules $x_{i}$, and the monetary authority's policy rule $\pi$, the policy $\tau_{i}$ maximizes the payoff to government $i$.

A cooperative equilibrium of this game is defined similarly, with (iii) replaced by this: $\left(i i i^{\prime}\right)$ given the private agents' decision rules $x_{i}$ and the monetary authority's policy rule $\pi$, the vector $\bar{\tau}$ maximizes the sum of the payoffs to the governments. (Notice that conditions (i), $(i i i)$, and $\left(i i i^{\prime}\right)$ require that the relevant policies be best responses, whereas condition (ii) has a fixed-point problem built into it.)

Throughout, we focus on symmetric equilibria, in which in addition to all private agents within a country choosing the same decision $\left(z_{i j}=x_{i}\right.$ all $\left.i, j\right)$, all governments in the union choose the same policy $\left(\tau_{i}=\tau_{j}\right.$ all $\left.i, j\right)$. We characterize the equilibria by working backward. Given nonmonetary policies $\bar{\tau}$ and private agent decisions $\bar{x}$, the monetary authority chooses $\pi$ to maximize union welfare (7). The resulting monetary policy function $\pi(\bar{\tau}, \bar{x})$ satisfies the first-order condition

$$
\sum_{i=1}^{N} V_{\pi}\left(\tau_{i}, x_{i}, x_{i}, \pi\right)=0,
$$

which in a symmetric equilibrium is simply $V_{\pi}=0$.

Each private agent maximizes (5), taking as given the nonmonetary policies $\bar{\tau}$, other private agents' decisions $\bar{x}$, and the monetary policy function $\pi(\bar{\tau}, \bar{x})$. The resulting best response function $X_{i}\left(\tau_{i}, x_{i}, \pi(\bar{\tau}, \bar{x})\right)$ satisfies the first-order condition

$$
V_{z}\left(\tau_{i}, z_{i j}, x_{i}, \pi\right)=0 .
$$


Let $\bar{x}(\bar{\tau})=\left(x_{1}(\bar{\tau}), \ldots, x_{N}(\bar{\tau})\right)$ denote the fixed point of the best response function, that is,

$$
x_{i}(\bar{\tau})=X_{i}\left(\tau_{i}, x_{i}(\bar{\tau}), \pi(\bar{\tau}, \bar{x}(\bar{\tau}))\right) \text { for all } i \text {. }
$$

In a noncooperative equilibrium, the government of country $i$ maximizes $V\left(\tau_{i}, x_{i}(\bar{\tau})\right.$, $\left.x_{i}(\bar{\tau}), \pi(\bar{\tau})\right)$. Let $\Pi(\bar{\tau})=\pi(\bar{\tau}, \bar{x}(\bar{\tau}))$ denote the monetary policy function $\pi(\bar{\tau}, \bar{x})$ evaluated at the private agent decision rules $\bar{x}(\bar{\tau})$. Then the government's first-order condition is

$$
V_{\tau}+\left(V_{z}+V_{x}\right) \frac{\partial x_{i}}{\partial \tau_{i}}+V_{\pi} \frac{\partial \Pi}{\partial \tau_{i}}=0
$$

where $\partial \Pi / \partial \tau_{i}=\partial \pi / \partial \tau_{i}+\sum_{j=1}^{N}\left(\partial \pi / \partial x_{j}\right)\left(\partial x_{j} / \partial \tau_{i}\right)$. Notice that $\partial \Pi / \partial \tau_{i}$ captures both the direct effects of changes in nonmonetary policy $\tau_{i}$ on inflation and the indirect effects through changes in private agents' decisions.

In a cooperative equilibrium, the governments jointly choose $\tau$ to maximize

$$
\sum_{i=1}^{N} V\left(\tau_{i}, x_{i}(\bar{\tau}), x_{i}(\bar{\tau}), \Pi(\bar{\tau})\right)
$$

Taking the first-order conditions and then imposing symmetry gives

$$
V_{\tau}+\left(V_{z}+V_{x}\right)\left[\frac{\partial x_{i}}{\partial \tau_{i}}+\sum_{j \neq i} \frac{\partial x_{j}}{\partial \tau_{i}}\right]+N V_{\pi} \frac{\partial \Pi}{\partial \tau_{i}}=0 .
$$

We can use these conditions to show the following:

Proposition 1 (Free-riding without commitment): Suppose that in a monetary union, there is a unique cooperative equilibrium with $V_{x} \neq 0$ and $\partial x_{j} / \partial \tau_{i} \neq 0$ for $i \neq j$. Then the monetary union has a free-riding problem, in the sense that the noncooperative and cooperative policies without commitment differ, and the cooperative equilibrium has strictly higher welfare than the noncooperative equilibrium. If either $V_{x}=0$ or $\partial x_{j} / \partial \tau_{i}=0$ in the cooperative equilibrium, then the monetary union has no free-riding problem, in the sense that the two equilibria coincide.

Proof. Substituting the first-order conditions for the monetary authority and the private agents into (12), we have that in a noncooperative equilibrium,

$$
V_{\tau}+V_{x} \frac{\partial x_{i}}{\partial \tau_{i}}=0
$$


Using similar substitutions, we have that in a cooperative equilibrium,

$$
V_{\tau}+V_{x}\left[\frac{\partial x_{i}}{\partial \tau_{i}}+\sum_{j \neq i} \frac{\partial x_{j}}{\partial \tau_{i}}\right]=0 .
$$

Comparing (14) and (15), we see that the policies in the two equilibria are different if and only if both $V_{x} \neq 0$ and $\partial x_{j} / \partial \tau_{i} \neq 0$ in the cooperative equilibrium. Since the governments in a cooperative equilibrium could feasibly choose the noncooperative policies, the uniqueness of the cooperative equilibrium implies that welfare is strictly higher in the cooperative equilibrium whenever the two equilibria differ. Q.E.D.

From (11) it is easy to see that

$$
\frac{\partial x_{j}}{\partial \tau_{i}}=X_{j \pi} \frac{\partial \Pi / \partial \tau_{j}}{1-X_{j x}}
$$

where $X_{j x}$ is the derivative of the fixed point of the best response function in (11) with respect to $x_{j}$. Notice that if the decisions of private agents do not depend on their predictions of inflation, so that $X_{j \pi}=0$, or if the inflation rate does not depend on the nonmonetary policies, so that $\partial \Pi / \partial \tau_{j}=0$, then $\partial x_{j} / \partial \tau_{i}=0$, and there is no free-rider problem.

At a superficial level, the free-rider problem seems to arise solely because inflation confers a common cost on all the countries in the union, whereas an individual country's government cares only about the effect of inflation on its own payoffs. The true source of the free-rider problem is, however, subtler. For example, suppose that $V_{x}=0$ - say, because there are no general equilibrium effects from private agents. Then the two equilibria coincide even though individual governments care only about the effects of inflation on their own countries. In this example, with $V_{x}=0$, the two equilibria coincide because of an envelope argument. In the cooperative equilibrium, the monetary authority chooses inflation to balance the costs and benefits, so that at the margin, an incremental change in inflation has no effect on union welfare. Starting at this outcome, a noncooperative government realizes that, at the margin, the induced effect of its policies on welfare through their effect on inflation is zero. In both the 
cooperative and noncooperative equilibria, therefore, a government's nonmonetary policies at the margin affect only that government's welfare. Hence, there is no free-rider problem.

When $V_{x} \neq 0$ and $\partial x_{j} / \partial \tau_{i} \neq 0$, however, there is a free-rider problem. Starting at the cooperative outcome, we know that if the government of country $i$ changes its nonmonetary policies, then the monetary authority responds by changing the inflation rate. At the margin, if we neglect the induced effects on private agent decisions $x$, then this change has no effect on welfare. The key is, however, that the induced change in the inflation rate does induce changes in private agent decisions $x$. This is the channel which leads to the free-rider problem. A change in the nonmonetary policy $\tau_{i}$ makes the private agents in all the countries predict a change in inflation, and this predicted change makes them change their actions. (Mechanically, we can see this from equation (16), which gives the change in private agent decisions in country $j$ due to changes in nonmonetary policy in country $i$. For this change to be nonzero, we need $\partial \Pi / \partial \tau_{i} \neq 0$ and $X_{j \pi} \neq 0$.) When $V_{x} \neq 0$, the change in private agent decisions due to a predicted change in inflation implies that a change in nonmonetary policy in country $i$ induces a change in welfare in country $j$ and thus leads to a free-rider problem. Later we will illustrate the detailed economic channels of the free-rider problem in our application of this theory to three specific types of nonmonetary policies.

We now show that if the monetary union has no time inconsistency problem, then it has no free-rider problem either. The union has no time inconsistency problem when its monetary authority has some commitment or reputational mechanism. To demonstrate that here, for simplicity, we just assume that the monetary authority can commit to its policies. A similar analysis would apply to the reputational equilibria that support commitment in a repeated game version of the model.

The timing in the commitment game is as follows. First the monetary authority chooses $\pi$, then governments choose $\tau_{i}$, and finally private agents choose $x_{i j}$.

A noncooperative equilibrium of this game is given by a monetary policy $\pi$, government 
nonmonetary policy functions $\tau_{i}(\pi)$, and private agent decision rules $x_{i}(\pi, \bar{\tau})$, such that $(i)$ for each private agent $i j$, and for all $\pi$ and $\bar{\tau}, x_{i}(\pi, \bar{\tau})$ solves

$$
\max _{z_{i j}} V\left(\tau_{i}, z_{i j}, x_{i}(\pi, \bar{\tau}), \pi\right)
$$

(ii) for each government $i$, for all $\pi$, given the nonmonetary policies of the other governments $\tau_{i^{\prime}}(\pi)$ and the private agent decision rules $x_{i}(\pi, \bar{\tau})$, the nonmonetary policy $\tau_{i}(\pi)$ maximizes the payoff to government $i$; and $(i i i)$ given the government nonmonetary policy functions $\tau_{i}$ and the private agent decision rules $x_{i}$, the monetary policy $\pi$ maximizes the monetary authority's payoff, or the union's overall welfare.

A cooperative equilibrium of the commitment game is defined similarly, but with (ii) replaced by this: $\left(i i^{\prime}\right)$ for all $\pi$, given the private agent decision rules $x_{i}(\pi, \bar{\tau})$, the nonmonetary policy $\tau_{i}(\pi)$ maximizes the sum of the payoffs to the governments.

We then have the following:

Proposition 2 (No free-riding with commitment): In a monetary union with commitment, the noncooperative and cooperative policies coincide, and welfare in the resulting equilibria is the same. Thus, with commitment, the union has no free-riding problem.

Proof. Consider private agent optimality. From (17) we know that the first-order condition for private agents in both equilibria is $V_{z}=0$ and that $x_{i}(\pi, \bar{\tau})$ depends only on $\pi$ and $\tau_{i}$ for all $i$, so that for $j \neq i$,

$$
\frac{\partial x_{i}}{\partial \tau_{j}}=0 .
$$

In the noncooperative equilibrium, the governments choose $\tau_{i}$ to maximize

$$
V\left(\tau_{i}, x_{i}(\pi, \bar{\tau}), x_{i}(\pi, \bar{\tau}), \pi\right)
$$

Using $V_{z}=0$, we can write the first-order condition in a noncooperative equilibrium as

$$
V_{\tau}+V_{x} \frac{\partial x_{i}}{\partial \tau_{i}}=0
$$


Acting cooperatively, the governments choose $\tau_{i}$ to maximize

$$
\sum_{i=1}^{N} V\left(\tau_{i}, x_{i}(\pi, \bar{\tau}), x_{i}(\pi, \bar{\tau}), \pi\right) .
$$

Using $V_{z}=0$ and (18), we see that the first-order condition for this problem reduces to (19). Clearly, the noncooperative and cooperative equilibria coincide. Thus, with commitment, there is no free-rider problem. Q.E.D.

The intuition for the differing results in the environments with and without commitment is as follows. In both environments, a government in a given country $i$ does not care directly about the nonmonetary policies or the private agent choices in any other country j. Without commitment, however, nonmonetary policies in other countries induce changes in the common inflation rate and thus changes in private agent choices in country $i$. This linkage leads nonmonetary policies in country $i$ to depend on nonmonetary policies in country $j$. This subtle linkage leads to a free-rider problem. With commitment, the links among governments in different countries are broken, and there is no free-rider problem.

Note that in our application to bank regulation, the monetary authority has essentially a zero-one decision on whether to bail out banks that are in danger of insolvency. This feature implies that, even though the monetary authority is maximizing, it does not set $V_{\pi}$ equal to zero. Inspecting (12) and (13), we see that if $V_{\pi} \partial \Pi / \partial \tau_{i}$ is not equal to zero, then an analog of Proposition 1 typically applies. Proposition 2 holds as stated.

\section{APPLICATIONS}

Now we apply this general theory to some common examples of nonmonetary policies and show that in a monetary union, lack of commitment in monetary policy leads to free-riding in nonmonetary policy. We also show that in such a situation, constraints on nonmonetary policies are desirable. 


\subsection{Labor Market Policy}

First we apply our theory to a type of nonmonetary policy that governments of members of a monetary union control: labor market policy. For this application, we use the classic model of time inconsistency in monetary policy due to Kydland and Prescott (1977) and Barro and Gordon (1983), in which ex post inflation reduces unemployment. We modify this model to allow governments in a monetary union to set labor market policies that determine the natural rate of unemployment in their own countries. We show that without commitment, the free-rider problem leads governments to adopt policies that result in higher unemployment and inflation than would occur in an efficient allocation. We also show that constraints imposed on labor market policies eliminate the free-rider problem and help mitigate but do not eliminate the time inconsistency problem.

Consider the following modified version of Kydland and Prescott's and Barro and Gordon's model. In this example, the natural rate of unemployment in country $i, \bar{u}\left(\tau_{i}\right)$, is affected by labor market policies in that country, denoted by $\tau_{i}$. For simplicity, let $\bar{u}\left(\tau_{i}\right)=$ $\bar{u}-\tau_{i}$. The realized unemployment rate $u_{i}$ is determined by the natural unemployment rate

and the log of the real wage $x_{i}-\pi$, which is the difference between the log of the nominal wage and the log of the price level. Since initial prices are given, $\pi$ is both the price level and the inflation rate. Specifically,

$$
u_{i}=x_{i}-\pi+\bar{u}\left(\tau_{i}\right)
$$

In this example, each private agent chooses a wage $z_{i j}$, and the wage in country $i$ is given by $x_{i}=\int z_{i j} d j$. The objective function of each private agent $i j$ is

$$
-\frac{1}{2}\left(z_{i j}-\pi\right)^{2}-\frac{a}{2} u_{i}^{2}-\frac{b}{2} \pi^{2}-\frac{c}{2} \tau_{i}^{2}
$$

where $a, b$, and $c$ are constants. The first term in this objective function provides a target real wage for the private agents, the second and the third terms reflect concerns over aggregate unemployment and inflation, and the last term captures the cost of altering labor market 
policies that affect the natural rate of unemployment. Substituting for $u_{i}$ from (20) and $\bar{u}\left(\tau_{i}\right)=\bar{u}-\tau_{i}$ gives private agents these payoffs:

$$
V\left(\tau_{i}, z_{i j}, x_{i}, \pi\right)=-\frac{1}{2}\left(z_{i j}-\pi\right)^{2}-\frac{a}{2}\left(x_{i}-\pi+\bar{u}-\tau_{i}\right)^{2}-\frac{b}{2} \pi^{2}-\frac{c}{2} \tau_{i}^{2} .
$$

The payoff to government $i$ is $\int V\left(\tau_{i}, z_{i j}, x_{i}, \pi\right) d i$, and the payoff to the union's monetary authority is the sum of the governments' payoffs. These payoff functions ensure that private agents choose their wages to be the expected value of inflation and that the monetary authority cares about the average rate of unemployment. (To see why this assumption matters, see the work of Chari, Kehoe, and Prescott 1989.) In much of the literature, the payoffs to the private agents are given (implicitly) by the first term on the right side of (22) and the payoffs to the monetary authority, by the second and third terms. We choose to combine these terms so that the governments and the monetary authority are benevolent.

Equilibria of the no commitment and commitment games in this example are defined exactly as in the theory section above. To show that the no commitment game has a free-rider problem, we need show only that $V_{x} \neq 0$ and $\partial x_{i}(\bar{\tau}) / \partial \tau_{j} \neq 0$ in the cooperative equilibrium. To do so, we first use the monetary authority's first-order condition to derive

$$
\pi(\bar{\tau}, \bar{x})=\frac{(1+a) \sum x_{i}+N a \bar{u}-a \sum \tau_{i}}{N(1+a+b)} .
$$

Next we note that the private agent's first-order condition yields $x_{i}=\pi$. Clearly, $x_{i}$ is the same for all $i$, and we denote it by $x$. Then $x(\bar{\tau})$ solves the fixed-point problem $x(\bar{\tau})=$ $\pi(\bar{\tau}, \bar{x}(\bar{\tau}))$, where $\bar{x}(\bar{\tau})=(x(\bar{\tau}), \ldots, x(\bar{\tau}))$. Using $(23)$, we have that

$$
x(\bar{\tau})=\frac{a}{b}\left(\bar{u}-\frac{\sum \tau_{i}}{N}\right) .
$$

Clearly, $\partial x_{i}(\bar{\tau}) / \partial \tau_{j}=-a / b N \neq 0$ as long as $a \neq 0$. To calculate the value of $V_{x}$, we need to solve for the cooperative equilibrium policies. It is straightforward to use the monetary authority's first-order condition to show that the cooperative equilibrium $(C)$ labor market policies are given by $\tau^{C}=\left[a+\left(a^{2} / b\right) \bar{u}\right] /\left[a+\left(a^{2} / b\right)+c\right]$. Using (23) and (24), we obtain

$$
V_{x}=\frac{a c \bar{u}}{a+\left(a^{2} / b\right)+c} .
$$


If $a c \bar{u} \neq 0$, we have that $V_{x} \neq 0$. From Proposition 1 , the following proposition is immediate:

Proposition 3 (Free-riding in labor market policies without commitment): In the game with no commitment, the monetary union has a free-rider problem, in the sense that the noncooperative and cooperative equilibria differ if ac $\bar{u} \neq 0$. If ac $\bar{u}=0$, then the union has no free-rider problem, in the sense that the two equilibria coincide.

If $a c \bar{u}=0$, then the monetary union has no time inconsistency problem in monetary policy. This condition is related to similar conditions in the literature that follows Kydland and Prescott (1977) and Barro and Gordon (1983). In that literature, $\bar{u}$ is a constant, and there is only one country. A standard result in the literature is that there is no time inconsistency problem if $a=0$ or if $\bar{u}=0$, that is, if the monetary authority does not have an incentive to reduce unemployment below the natural rate. In our model, in which the natural rate can be affected by labor market policies, if $c=0$, then each government would simply set its policies so that the natural rate is zero, and there would be no time inconsistency problem in monetary policy. Thus, Proposition 3 essentially says that whenever there is a time inconsistency problem in monetary policy, there is a free-rider problem in labor market policy.

It is easy to show that the equilibrium inflation rate under noncooperation $(N)$ is

$$
\pi^{N}=\frac{a c \bar{u} / b}{a+\left(a^{2} / b N\right)+c}
$$

and the equilibrium inflation rate under cooperation $(C)$ is

$$
\pi^{C}=\frac{a c \bar{u} / b}{a+\left(a^{2} / b\right)+c} .
$$

Clearly, the noncooperative rate of inflation $\pi^{N}$ is greater than the corresponding cooperative rate $\pi^{C}$. Notice that the noncooperative inflation rate rises monotonically with the number of countries. In this sense, the free-rider problem gets worse as the number of countries gets larger. 
The free-rider problem can be eliminated by imposing constraints on the labor market policies of the union's member governments. The following corollary is immediate.

Corollary to Proposition 3 (Labor market policy constraints and the free-rider problem): In a monetary union without commitment, if each government is required to set its labor market policy $\tau_{i} \geq \tau^{C}$, then the union has no free-rider problem, in the sense that the noncooperative equilibrium attains the same levels as the cooperative equilibrium.

Another way to interpret this corollary is as follows. Consider the problem of designing the constraints on labor market policy in the symmetric noncooperative equilibrium in order to reach the highest attainable level of welfare. Inspection of the cooperative problem makes clear that the highest attainable level of welfare is the level in the cooperative equilibrium. In the noncooperative equilibrium, this level of welfare can be reached by setting the constraint $\tau_{i} \geq \tau^{C}$

Clearly, Proposition 2 applies to this application of our theory to labor market policy, and thus with commitment, there is no free-rider problem. Under commitment, the cooperative rate of inflation is zero.

Notice that the constraints on labor market policy that eliminate the free-rider problem in labor market policy also help mitigate the time inconsistency problem in monetary policy because they lower inflation from $\pi^{N}$ to $\pi^{C}$. They do not, however, eliminate the time inconsistency problem: $\pi^{C}$ is still positive and thus higher than the cooperative rate of inflation with commitment, which is zero.

Note that the time inconsistency problem arises even if the monetary union consists of a single country. As is well-known, welfare is often lower without commitment in monetary policy than with such commitment. The labor market constraints discussed here obviously cannot solve the time inconsistency problem. All these constraints do is help solve the freerider problem by reproducing the outcomes that would occur if the monetary union consisted of a single country. In this sense, even though the free-rider problem arises because there 
is a time inconsistency problem, solving the free-rider problem does not eliminate the time inconsistency problem.

\subsection{Fiscal Policy}

Now we apply our theory to a second type of nonmonetary policy: fiscal policy. We assume here that each of the many governments in the monetary union issues nominal debt to their residents in order to spend and smooth consumption over time. The union's single monetary authority chooses a common inflation rate. This inflation reduces the real return on debt and effectively serves as a kind of partial default on it. We show that when the monetary authority cannot effectively commit to its monetary policy, the union has a freerider problem: governments issue too much debt, inflation is too high, and output is too low relative to the cooperative levels. This free-rider problem can be solved by imposing constraints on the amount of debt that governments can issue. Such constraints lead to the cooperative levels of inflation and output.

We also show that if the monetary authority can commit to its policies, constraints on fiscal policy are unnecessary and possibly harmful. From this perspective, critics of these constraints, such as Buiter, Corsetti, and Roubini. (1993) must be implicitly assuming that the monetary authority can overcome its time inconsistency problem.

Consider a two-period model with $N$ identical countries indexed $i=1, \ldots, N$ united in a monetary union. The preferences of consumer $j$ in country $i$ are given by

$$
U\left(c_{0 i j}\right)+V\left(g_{i}\right)+\beta U\left(c_{1 i j}\right),
$$

where $c_{0 i j}$ and $c_{1 i j}$ denote private consumption in the two periods, $g_{i}$ is government consumption in period $0 ; U\left(c_{t i j}\right)$ for $t=0,1$ is the utility from private consumption; $\beta$ is the discount factor; and $V\left(g_{i}\right)$ is the utility from government consumption. We normalize the price level in period 0 to be 1 and let $\pi$ denote the unionwide gross inflation rate between periods 0 and 1 . We model monetary policy as the choice of the price level that produces each period's inflation rate $\pi$. 
In each country $i$, output in period 0 is a constant $\omega$, while output in period 1 is $y\left(\pi, T_{i}\right)$, where $T_{i}$ denotes real tax revenues in period 1 . We assume that $y\left(\pi, T_{i}\right)$ is decreasing in both $\pi$ and $T$; both inflation and taxes distort decisions and therefore reduce output. We assume that consumers have access to a linear savings technology with exogenous gross return $1+r$. This assumption ensures that real interest rates are unaffected by policy.

Consider next the budget constraints of the governments and the consumers. For simplicity, assume that government consumption $g_{i}$ is financed entirely by debt issued to country $i$ consumers in period 0 and paid for by distortionary taxation of those consumers in period 1 . In period 0 , the government of each country $i$ issues to consumers claims to $B_{i}$ units of currency payable in period 1 . Let $1+R$ denote the nominal interest rate on this debt; then the budget constraint of government $i$ is

$$
g_{i}=\frac{B_{i}}{1+R}
$$

in period 0 and

$$
T_{i}=\frac{B_{i}}{\pi}
$$

in period 1. Let $k_{i j}$ denote the amount that consumers save in the storage technology and $d_{i j}$, the amount that they save by holding government debt. The budget constraints of consumer $j$ in country $i$ are then

$$
c_{0 i j}=\omega-k_{i j}-d_{i j}
$$

and

$$
c_{1 i j}=y\left(\pi, T_{i}\right)-T_{i}+(1+r) k_{i j}+(1+R) \frac{d_{i j}}{\pi}
$$

We consider symmetric allocations across consumers in a given country so that, for all $j, d_{i j}=d_{i}, k_{i j}=k_{i}, c_{0 i j}=c_{0 i}$, and $c_{1 i j}=c_{1 i}$. In such symmetric allocation, each consumer pays $d_{i}=B_{i} /(1+R)$ for claims to debt in period 0 and receives a repayment (including interest) of $B_{i}$ in period 1 . We assume throughout that $\omega$ is sufficiently small so 
that consumers choose to save. That is, we assume that the equilibrium is interior, in the sense that both $k_{i}$ and $d_{i}$ are positive. Let total debt $\bar{d}=\left(d_{1}, \ldots, d_{N}\right)$ and total repayments made $\bar{B}=\left(B_{1}, \ldots, B_{N}\right)$ summarize the debt contracts.

The timing of this model without commitment is as follows. In period 0 , the governments choose their promised repayments $B_{i}$. Consumers then choose how much to save in the storage technology $k_{i j}$ and how much nominal debt to hold $d_{i j}$. In period 1 , the monetary authority chooses the common inflation rate $\pi$ as a function of the promised nominal repayments $\bar{B}$ and the saved amounts $\bar{k}=\left(k_{1}, \ldots, k_{N}\right)$. Finally, the governments choose real tax revenues $T_{i}$ to satisfy their budget constraints.

To set up the equilibrium, we work back from the end of period 1. At that point, given $\pi$ and $B_{i}$, a government chooses to raise tax revenues to satisfy $T_{i}=B_{i} / \pi$. At the beginning of period 1 , the monetary authority chooses $\pi$ to solve

$$
\max _{\pi} \frac{1}{N} \sum_{i=1}^{N} U\left(y\left(\pi, \frac{B_{i}}{\pi}\right)+(1+r) k_{i}\right) .
$$

In (29) we have integrated the consumers' budget constraints in period 1, used the government's period 1 budget constraint to cancel terms, and then dropped irrelevant terms, such as the discount factor and terms relating to period 0 . The first-order conditions are

$$
\frac{1}{N} \sum_{i=1}^{N} U^{\prime}\left(c_{1 i}\right)\left[y_{\pi i}-\frac{B_{i}}{\pi^{2}} y_{T i}\right]=0,
$$

where $y_{\pi i}$ and $y_{T i}$ denote the partial derivatives of $y\left(\pi, B_{i} / \pi\right)$ with respect to the first and second arguments. Let $\pi(\bar{x}, \bar{k})$ denote the resulting monetary policy rule.

Now consider the decisions of the consumers. These consumers have two ways to save: by holding nominal debt and by using the storage technology. Clearly, in any interior equilibrium, the real rates of return on government debt and storage must be equal, so that

$$
1+r=\frac{1+R}{\pi}
$$

The first-order condition relating marginal utilities in periods 0 and 1 is then given by

$$
U^{\prime}\left(c_{i 0}\right)=\beta(1+r) U^{\prime}\left(c_{i 1}\right)
$$


and is referred to as the first-order condition for saving.

Finally, consider the decision of government $i$ at the beginning of period 0 . It is convenient to formulate the government's problem as a Ramsey problem in which the government chooses both the debt and the decisions of consumers subject to the consumers' first-order conditions. In the noncooperative equilibrium, the government of country $i$, taking other countries' debt contracts and saving decisions as given, chooses $B_{i}$ and $k_{i}$ to maximize

$$
\begin{aligned}
& U\left(\omega-\frac{B_{i}}{(1+r) \pi(\bar{B}, \bar{k})}-k_{i}\right) \\
& +V\left(\frac{B_{i}}{\pi(\bar{B}, \bar{k})}\right)+\beta U\left(y\left(\pi(\bar{B}, \bar{k}), \frac{B_{i}}{\pi(\bar{B}, \bar{k})}\right)+(1+r) k_{i}\right)
\end{aligned}
$$

subject to the first-order condition for consumer savings (31), where we have used the budget constraints of the consumers and the government to substitute out variables.

In the cooperative equilibrium, the debt and storage levels $\bar{B}$ and $\bar{k}$, are chosen to maximize

$$
\begin{aligned}
& \frac{1}{N} \sum_{i=1}^{N}\left[U\left(\omega-\frac{B_{i}}{(1+r) \pi(\bar{B}, \bar{k})}-k_{i}\right)+V\left(\frac{B_{i}}{\pi(\bar{B}, \bar{k})}\right)\right. \\
& \left.+\beta U\left(y\left(\pi(\bar{B}, \bar{k}), \frac{B_{i}}{\pi(\bar{B}, \bar{k})}\right)+(1+r) k_{i}\right)\right]
\end{aligned}
$$

subject to the first-order condition for consumer savings (31) in each country.

A noncooperative equilibrium here is a monetary policy rule $\pi(\bar{B}, \bar{k})$ that solves $(29)$ and allocations $\left(\bar{B}_{N}, \bar{k}_{N}\right)$ that solve (32). A cooperative equilibrium is a monetary policy rule $\pi(\bar{B}, \bar{k})$ that solves $(29)$ and allocations $\left(\bar{B}_{C}, \bar{k}_{C}\right)$ that solve $(34)$.

While this setup can be mapped into the language of the general theory section, for convenience, we analyze the noncooperative and cooperative equilibria directly. We begin with a simple lemma that simplifies this analysis.

LEMMA 1. In a symmetric noncooperative equilibrium, the solution to the government's problem (32) coincides with the solution to a relaxed version of that problem in which the 
first-order condition for consumer savings in each country is dropped as a constraint. A similar result holds for the symmetric cooperative equilibrium.

Proof. To prove this lemma, we first show that at any symmetric allocation in the symmetric equilibrium,

$$
\frac{\partial \pi(\bar{B}, \bar{k})}{\partial k_{i}}=0
$$

We can compute this derivative by differentiating the monetary authority's first-order condition (30), which defines $\pi(\bar{B}, \bar{k})$. This first-order condition, with the optimal value $\pi(\bar{B}, \bar{k})$ substituted in, can be written as

$$
\frac{1}{N} \sum_{i=1}^{N} U^{\prime}\left(c_{1 i}(\bar{B}, \bar{k})\right)\left[y_{\pi i}(\pi(\bar{B}, \bar{k})), \frac{B_{i}}{\pi(\bar{B}, \bar{k})}-\frac{B_{i}}{\pi(\bar{B}, \bar{k})^{2}} y_{T i}(\pi(\bar{B}, \bar{k})), \frac{B_{i}}{\pi(\bar{B}, \bar{k})}\right]=0
$$

where $c_{1 i}(\bar{B}, \bar{k})$ is short-hand notation for the right side of (28) evaluated at $\pi(\bar{B}, \bar{k})$. Taking the derivative of (36) and using the fact that at a symmetric allocation (30) holds, we see that (36) reduces to

$$
y_{\pi i}-\frac{B_{i}}{\pi^{2}} y_{T i}=0
$$

Since the optimal $\pi$ does not vary with $k_{i}$, (35) follows.

Now consider the first-order condition for $k_{i}$ in the lemma's relaxed problem. Using (35), we know that this first-order condition is simply

$$
U^{\prime}\left(c_{i 0}\right)=\beta(1+r) U^{\prime}\left(c_{i 1}\right)
$$

But this implies that the solution to the relaxed problem is also feasible for the government's original problem. Similar logic applies in the symmetric cooperative equilibrium. Q.E.D.

From the lemma, (37), and the consumers' first-order condition (38), we know that the first-order condition for debt in the symmetric noncooperative equilibrium can be written as

$$
\left[\left(y_{T}-1\right) U^{\prime}\left(c_{0}\right)+V^{\prime}(g)\right]+\left[U^{\prime}\left(c_{0}\right)-V^{\prime}(g)\right]\left(\frac{B}{\pi} \frac{\partial \pi}{\partial B}\right)=0
$$


while the first-order condition for debt in the symmetric cooperative equilibrium is

$$
\left[\left(y_{T}-1\right) U^{\prime}\left(c_{0}\right)+V^{\prime}(g)\right]+N\left[U^{\prime}\left(c_{0}\right)-V^{\prime}(g)\right]\left(\frac{B}{\pi} \frac{\partial \pi}{\partial B}\right)=0 .
$$

The first-order condition for storage in both of these equilibria is simply (38).

The following proposition is then immediate:

Proposition 4 (Free-riding in fiscal policies without commitment): A monetary union with no commitment has a free-rider problem, in the sense that the noncooperative and cooperative equilibria differ, and the cooperative equilibrium has strictly higher welfare than the noncooperative equilibrium.

The free-rider problem can be eliminated by imposing constraints on the debt policies of the union's member governments. To see this, consider trying to support the cooperative allocations as noncooperative allocations subject to an upper limit on debt repayments $B_{i} \leq B_{C}$. We establish our result by showing that under sufficient conditions, the increment to welfare of a marginal increase in debt is positive at the cooperative allocations. This result implies that for a noncooperative government, the debt constraint will bind at those allocations. To see that, note that the left side of (39) is the increment to welfare under a noncooperative government from an increase in debt. When evaluated at the cooperative allocations which satisfy (40), this increment equals

$$
(N-1)\left[V^{\prime}(g)-U^{\prime}\left(c_{0}\right)\right]\left(\frac{B}{\pi} \frac{\partial \pi}{\partial B}\right) .
$$

Letting $\eta=(B / \pi)(\partial \pi / \partial B)$ denote the elasticity of nominal debt with respect to inflation when evaluated at the cooperative equilibrium allocations, we have this corollary.

Corollary to Proposition 4 (Debt constraints and the free-rider problem): In a monetary union without commitment, if $0<\eta<1 / N$ and each government is required to set its debt repayments $B_{i} \leq B_{C}$, then the union has no free-rider problem, in the sense that the noncooperative equilibrium attains the same levels as the cooperative equilibrium. 
Proof. We need to show that the increment to welfare in (41) is positive when the elasticity satisfies $0<\eta<1 / N$. To do so, rewrite (40) as

$$
\left[V(g)-U^{\prime}\left(c_{0}\right)\right](1-N \eta)+U^{\prime}\left(c_{0}\right) y_{T}=0
$$

Since $\eta<1 / N$, the term $(1-N \eta)$ is positive. Since the term $y_{T}$ is negative, we know that

$$
V^{\prime}(g)-U^{\prime}\left(c_{0}\right)>0
$$

which, since $\eta>0$, implies that (41) is positive. Q.E.D.

It is easy to show that if $y(\pi, T)$ is linear in its arguments, then $\eta=(1 / 2) N$, which obviously satisfies the condition in the corollary $0<\eta<1 / N$.

This corollary can be interpreted in another way. Consider the problem of designing the constraints on fiscal policy in the symmetric noncooperative equilibrium in order to reach the highest attainable level of welfare. Inspection of the cooperative problem makes it clear that the highest attainable level of welfare is the level in the cooperative equilibrium. In the noncooperative equilibrium, this welfare level can be reached by setting the constraint $B_{i} \leq B_{C}$

We now show that the analog of Proposition 2 applies to our fiscal policy application. That is, when a monetary authority can commit, the cooperative and noncooperative equilibria coincide; hence, binding constraints on future debt issues can only reduce welfare.

To show this, we make one change in the timing of the model to allow for commitment by the monetary authority. Instead of waiting until period 1 , the monetary authority chooses the inflation rate $\pi$ first, at the start of period 0 . Then the governments choose their promised repayments $B_{i}$, and consumers choose how much to store $k_{i j}$ and how much nominal debt to hold $d_{i j}$. In period 1 , finally, the governments choose real tax revenues $T_{i}$ to satisfy their budget constraints.

It should be clear that the problem of the government in the noncooperative regime 
reduces to this:

$$
\max _{B_{i}, k_{i}} U\left(\omega-\frac{B_{i}}{(1+r) \pi}-k_{i}\right)+V\left(\frac{B_{i}}{\pi}\right)+\beta U\left(y\left(\pi, \frac{B_{i}}{\pi}\right)+(1+r) k_{i}\right)
$$

subject to the first-order condition for consumer savings. The analogous problem in the cooperative regime is to

$$
\max _{\bar{B}, \bar{k}} \frac{1}{N} \sum_{i=1}^{N}\left[U\left(\omega-\frac{B_{i}}{(1+r) \pi}-k_{i}\right)+V\left(\frac{B_{i}}{\pi}\right)+\beta U\left(y\left(\pi, \frac{B_{i}}{\pi}\right)+(1+r) k_{i}\right)\right]
$$

subject also to the first-order condition for consumer savings. By inspection, we know that the solutions to these two problems are identical, and Proposition 2 holds, so that in a monetary union with commitment, the noncooperative and cooperative policies coincide, and welfare in the resulting equilibria is the same. Thus, with commitment, the union has no free-riding problem.

Propositions 2 and 4 imply that a time inconsistency problem in monetary policy is at the heart of a free-rider problem in fiscal policy. They also imply that the question of whether debt constraints are desirable is intimately connected to the extent to which the monetary authority can commit to monetary policy. From Proposition 4 and the above discussion, we know that if such commitment is not possible, then appropriately chosen debt constraints raise welfare, whereas if such commitment is possible, then debt constraints can only reduce it.

The monetary union with commitment is broadly similar to the economies studied in an extensive literature that has discussed the gains from international cooperation in setting fiscal policy. (See, for example, the work of Chari and Kehoe 1990 and Canzoneri and Diba 1991.) As noted in the introduction, this literature shows that cooperation is desirable if a country's fiscal policy affects world real interest rates. In our fiscal policy application, cooperation offers no gains under commitment because we have effectively assumed that the monetary union is small in the world, in the sense that the world interest rate is independent of the fiscal policy decisions of the union's members. We have done so by having a linear storage technology. 
However, suppose that we consider instead a model in which the real interest rate is affected by the decisions of the governments in the monetary union. In such a formulation, even with commitment by the monetary authority, the noncooperative and cooperative equilibria do not coincide. This is because any country's spending decision affects the world interest rate and, hence, other countries' welfare. Since these types of gains to cooperation are not especially related to the formation of a monetary union, we abstract from them.

\subsection{Bank Regulation}

Now we apply our theory to a third type of nonmonetary policy: bank regulation. Here the time inconsistency problem arises because the union's monetary authority cannot commit to not bailing out insolvent banks. Each country's government policy consists of determining the level of regulation of banks. Here the free-rider problem leads to lax regulation of banks, frequent bank bailouts, and a high rate of inflation. The general argument in Propositions 1 and 2 , that the time inconsistency problem leads to a free-rider problem, applies here, with the modifications discussed at the end of the theory section. Here we see that unionwide restrictions on bank regulation are desirable.

We assume that private agents' funds deposited in banks are fully insured, banks have limited liability, and the monetary authority bails out insolvent banks by printing money to pay off their depositors. Deposit insurance, together with limited liability, creates an incentive for banks to take on excessive risk. We assume that governments regulate banks to limit risk-taking. In this application, the free-rider problem leads governments to regulate too little and leads banks to take on too much risk compared to how they would behave in the efficient allocation.

The environment here is as follows. The monetary union consists of $N$ countries indexed $i=1, \ldots, N$. The aggregate state of the union's economy is $s \in\{H, L\}$, where $H$ denotes a boom (or a high state) and $L$ denotes a recession (or a low state). The probabilities of $H$ and $L$ are $\mu_{H}$ and $\mu_{L}$, respectively, where $\mu_{H}+\mu_{L}=1$. Output is produced as follows. 
Each country $i$ has a large number of projects, indexed by $z_{i} \in[0,1 / 2]$. A project of type $z$ yields a return $R$ per unit of investment when it succeeds and 0 otherwise. A project's probability of success is $p_{H}(z)=(1 / 2)+z$ in a boom and $p_{L}(z)=(1 / 2)-z$ in a recession. We will show that in each country $i$, only one type of project-say, $z_{i}$ - will be chosen to be financed by the country's banks. The total output in country $i$ in state $s \in\{H, L\}$ is $p_{s}\left(z_{i}\right) R$. Notice that when projects with a higher value of $z$ are chosen, the distribution of output is a mean-preserving spread of the output when projects with a lower value of $z$ are chosen.

This monetary union has many banks. Each bank can finance up to one unit of investment. A bank in country $i$ obtains funds from depositors who are paid an interest rate $r_{i}$. Banks have limited liability, in that they must pay depositors only if bank receipts exceed bank obligations. If bank receipts fall short of obligations, then banks pay zero, and the monetary authority pays off the depositors by liquidating the bank's assets and printing money to cover any shortfall. The government of country $i=1, \ldots, N$ can do some costly supervision at a level of $\tau_{i}$ and prohibit banks from financing projects with $z>\tau_{i}$. This supervision of bank activities is what will represent bank regulation in this economy.

We now describe optimal behavior by banks for a given inflation rate $\pi$ and given supervision levels $\bar{\tau}=\left(\tau_{1}, \ldots, \tau_{N}\right)$. A bank's maximization problem is to choose which type of project to fund. A bank in country $i$, taking as given the interest rate $r_{i}$ on its deposits and the government supervision level $\tau_{i}$, chooses project type $z$ to maximize profits:

$$
q_{H i} \max \left\{p_{H}(z) R-r_{i}, 0\right\}+q_{L i} \max \left\{p_{L}(z) R-r_{i}, 0\right\}
$$

subject to $z \leq \tau_{i}$. Here, $q_{H i}$ and $q_{L i}$ are the prices in country $i$ for one unit of consumption in a boom and a recession (state $H$ and $L$ ), respectively.

For some given policies $\pi$ and $\bar{\tau}$ and state prices $q_{s i}$, for $i=1, \ldots, N, s=H, L$, a competitive banking equilibrium consists of portfolio rules $z_{i}\left(\tau_{i}\right)$ and deposit rates $r_{i}\left(\tau_{i}\right)$ such that $(i) z_{i}\left(\tau_{i}\right)$ solves (45) given $r_{i}\left(\tau_{i}\right)$ and $(i i)$ profits as defined in (45) are zero. Then we 
have the following:

LEMMA 2. In a competitive banking equilibrium, $z_{i}\left(\tau_{i}\right)=\tau_{i}$ and $r_{i}=p_{H}\left(z_{i}\left(\tau_{i}\right)\right) R$.

Proof. Since profits are zero in equilibrium, each term in (45) is zero. We drop the $i$ subscript for simplicity. Since $p_{H}(z) \geq p_{L}(z)$, we know that $r=p_{H}(z) R$ and $p_{L}(z) R-r \leq 0$. To see that the constraint $z \leq \tau$ binds, suppose, by way of contradiction, that it doesn't, that in equilibrium $z<\tau$. Then consider the problem of an individual bank. For this bank, increasing $z$ increases $p_{H}(z) R-r$ and, thus, increases the first term in (45). The second term is unchanged since $\max \left\{p_{L}(z) R-r_{i}, 0\right\}$ is zero at the original value of $z$ and increasing $z$ lowers $p_{L}(z) R-r$; that is, the maximum value remains at zero. Thus, increasing $z$ increases profits, which contradicts profit maximization. Q.E.D.

We assume that the objective function for the private agents and the government of country $i$ is

$$
\sum_{s} \mu_{s} U\left(y_{s i}, \pi_{s}\right),
$$

where $y_{s i}$ denotes output in country $i$ and $\pi_{s}$ denotes the common inflation rate across countries, both in state $s$. We assume that private agents cannot share risk across countries, so that each agent simply consumes the output of country $i$. We also assume that the utility function is increasing in output and decreasing in the inflation rate. Output in each country $i$ is given by the returns from the banks' projects less the costs of supervising banks, $e\left(\tau_{i}\right)$, which is increasing in $\tau_{i}$. From the lemma, we know that all banks in a given country choose projects of the same type $z_{i}$, so that total output in country $i$ is given by $y_{s}\left(z_{i}, \tau_{i}\right)=p_{s}\left(z_{i}\right) R-e\left(\tau_{i}\right)$.

In this economy, the monetary authority is required to print money to bail out any bank that cannot pay off its depositors, that is, when $r_{i}<p_{s}\left(z_{i}\right) R$. An inflation rate of $\pi$ raises revenues of $\pi M$, where $M$ is the union's initial money stock, which we normalize to 1 . 
Thus, the monetary authority must set $\pi$ so that in each state $s$

$$
\pi_{s}(\bar{r}, \bar{z})=\sum_{i} \max \left\{r_{i}-p_{s}\left(z_{i}\right) R, 0\right\}
$$

where $\bar{r}=\left(r_{1}, \ldots, r_{N}\right)$ and $\bar{z}=\left(z_{1}, \ldots, z_{N}\right)$.

A noncooperative equilibrium here is given by a vector of bank supervision levels $\bar{\tau}$ that solves

$$
\max \sum_{s} \mu_{s} U\left(y_{s}\left(z_{i}(\bar{\tau}), \tau_{i}\right), \pi_{s}(\bar{r}(\bar{\tau}), \bar{z}(\bar{\tau}))\right)
$$

along with a competitive banking equilibrium $(\bar{r}(\bar{\tau}), \bar{z}(\bar{\tau}))$ and a monetary policy function $\pi$ that solves (47). A cooperative equilibrium is defined similarly except that the vector of supervision levels $\bar{\tau}$ maximizes the sum of objective functions across countries.

The logic of the general setup discussed at the end of the theory section can be applied to this bank regulation application. To see how, let $x_{i}$ be the vector $\left(x_{i r}, x_{i z}\right)=\left(r_{i}, z_{i}\right)$ and $\pi$ be the vector $\left(\pi_{L}, \pi_{H}\right)$. To keep the notation simple, let the monetary authority either bail out all insolvent banks, by setting $\pi_{s}=\pi_{s}(\bar{r}, \bar{z})$, or not bail out any insolvent bank, by setting $\pi_{s}=0$. Let the indicator variable $d=1$ if there is a bailout and $d=0$ if not. Since banks within each country all solve the same problem, we need only consider a representative bank for each country. Hence, there is no $z_{i j}$ in payoffs. Then the payoff to a government of country $i$ is given by

$$
V\left(\tau_{i}, x_{i}, \pi\right)=\sum_{s} \mu_{s} U\left(y_{s}\left(z_{i}, \tau_{i}\right), \pi_{s}\right) \text { if either } r_{i} \leq p_{s}\left(z_{i}\right) R \text { or } d=1,
$$

and otherwise $V\left(\tau_{i}, x_{i}, \pi\right)$ equals an arbitrarily large negative number, say, $-K$. This payoff to the government coincides with the payoff in (46) if either the banks in that country are solvent or there is a bailout. The payoff to the monetary authority is then $\sum_{i} V\left(\tau_{i}, x_{i}, \pi\right)$. Since the cost of not bailing out insolvent banks is arbitrarily large, the optimal choice for the monetary authority is to bail out all insolvent banks. 
Now consider applying the extension of Proposition 1 that we referred to at the end of the theory section. Government $i$ 's first-order condition under noncooperation for $\tau_{i}$ is the analog of (12):

$$
V_{\tau}+\frac{\partial V}{\partial z_{i}} \frac{\partial z_{i}}{\partial \tau_{i}}+\frac{\partial V}{\partial r_{i}} \frac{\partial r_{i}}{\partial \tau_{i}}+V_{\pi} \frac{\partial \Pi}{\partial \tau_{i}}=0 .
$$

The first-order condition for $\tau_{i}$ under cooperation is the analog of (13):

$$
V_{\tau}+\frac{\partial V}{\partial z_{i}} \frac{\partial z_{i}}{\partial \tau_{i}}+\frac{\partial V}{\partial r_{i}} \frac{\partial r_{i}}{\partial \tau_{i}}+N V_{\pi} \frac{\partial \Pi}{\partial \tau_{i}}=0
$$

This uses the feature that here neither $r_{i}$ nor $z_{i}$ varies with $\tau_{j}$. Since $V_{\pi} \neq 0$ and $\partial \Pi / \partial \tau_{i} \neq 0$, policies under cooperation and noncooperation differ. We have proven the following proposition:

PROPOSITION 5 (Free-riding in bank regulation without commitment): Without commitment, the monetary union has a free-riding problem, in the sense that policies under noncooperation and cooperation differ.

The mechanism that leads to the free-rider problem here is as follows. When bank supervision by a government slackens, banks under its supervision take on riskier portfolios, and in a recession, the monetary authority must make larger bailouts. These larger bailouts lead to higher inflation and lower welfare. In a noncooperative equilibrium, each government trades off the gains from slacker supervision against the costs it bears from higher inflation. In particular, each government ignores the costs on others of the higher inflation that its actions induce. In a cooperative equilibrium, the gains from slacker supervision are traded off against the costs that all bear from higher inflation. These trade-offs lead to higher inflation and lower welfare in the noncooperative equilibrium.

One way to mitigate the free-rider problem with regard to this type of nonmonetary policy is to have countries set a mutually agreed upon level of bank supervision. Here that level should be the cooperative level. Finally, Proposition 2 holds as stated for this 
environment, so that when there is commitment by the monetary authority, there is no free-rider problem.

\section{CONCLUSION}

We have shown that time inconsistency problems in monetary policy induce a novel type of free-rider problem in nonmonetary policies within monetary unions. The source of the free-rider problem is the behavior of private agents. We have demonstrated that the free-rider problem can be solved, or at least mitigated, by setting constraints on nonmonetary policies. When a union's monetary authority cannot commit to its policies, such constraints lead to better monetary as well as nonmonetary policies. With commitment, however, nonmonetary policy constraints only impose costs.

Here we have also illustrated our theory by applying it to three common types of nonmonetary policies available to governments of countries in a monetary union.

Altogether, our analysis helps explain the divergent experiences of monetary unions in Europe and Latin America and pinpoints some ingredients essential for a successful union. 


\section{References}

Barro, Robert J., and David B. Gordon. (1983). "A Positive Theory of Monetary Policy in a Natural Rate Model." Journal of Political Economy 91, 589-610.

Beetsma, Roel, and Harald Uhlig. (1999). "An Analysis of the Stability and Growth Pact." Economic Journal 109, 546-571.

Buiter, Willem, Giancarlo Corsetti, and Nouriel Roubini. (1993). "Excessive Deficits: Sense and Nonsense in the Treaty of Maastricht." Economic Policy: A European Forum 8, $57-100$.

Canzoneri, Matthew B., and Behzad T. Diba. (1991). "Fiscal Deficits, Financial Integration, and a Central Bank for Europe." Journal of the Japanese and International Economy 5, 381-403.

Chari, V. V., and Patrick J. Kehoe. (1990). "International Coordination of Fiscal Policy in Limiting Economies." Journal of Political Economy 98, 617-636.

Chari, V. V., and Patrick J. Kehoe. (2007). "On the Need for Fiscal Constraints in a Monetary Union." Journal of Monetary Economics, 54, 2399-2408.

Chari, V. V., Patrick J. Kehoe, and Edward C. Prescott. (1989). "Time Consistency and Policy." In Modern Business Cycle Theory, edited by Robert J. Barro, pp. 265-305. Cambridge, MA: Harvard University Press.

Cooper, Russell W., and Hubert Kempf. (2001a). "Dollarization and the Conquest of Hyperinflation in Divided Societies." Federal Reserve Bank of Minneapolis Quarterly Review 25 (Summer), 3-12.

Cooper, Russell W., and Hubert Kempf. (2001b). "On Dollarization." Manuscript, Boston University.

Cooper, Russell W., and Hubert Kempf. (2004). "Overturning Mundell: Fiscal Policy in a Monetary Union." Review of Economic Studies 71, 371-396.

Dixit, Avinash, and Luisa Lambertini. (2001). "Monetary-Fiscal Policy Interactions and 
Commitment versus Discretion in a Monetary Union." European Economic Review 45, 977-987.

Giovannini, Alberto, and Luigi Spaventa. (1991). "Fiscal Rules in the European Monetary Union: A No-Entry Clause." CEPR Discussion Paper 516, Centre for Economic Policy Research, January 1991. Reprinted in The Debate on Money in Europe, 1995, edited by Alberto Giovannini, pp. 231-258. Cambridge, MA: MIT Press, 1995.

Jones, Mark P., Pablo Sanguinetti, and Mariano Tommasi. (2000). "Politics, Institutions, and Fiscal Performance in a Federal System: An Analysis of the Argentine Provinces." Journal of Development Economics 61, 305-333.

Kydland, Finn E., and Edward C. Prescott. (1977). "Rules Rather Than Discretion: The Inconsistency of Optimal Plans." Journal of Political Economy 85, 473-491.

Nicolini, Juan Pablo, Josefina Posadas, Juan Sanguinetti, Pablo Sanguinetti, and Mariano Tommasi. (2002). "Decentralization, Fiscal Discipline in Sub-National Governments, and the Bailout Problem: The Case of Argentina." Research Network Working Paper R-467, Inter-American Development Bank, August 2002.

Sibert, Anne. (1992). "Government Finance in a Common Currency Area." Journal of International Money and Finance 11, 567-578.

Tommasi, Mariano, Sebastian Saiegh, and Pablo Sanguinetti. (2001). "Fiscal Federalism in Argentina: Policies, Politics, and Institutional Reform." Economia: Journal of the Latin American and Caribbean Economic Association 1, 157-200.

Uhlig, Harald. (2002). "One Money, But Many Fiscal Policies in Europe: What Are the Consequences?" CEPR Discussion Paper 3296, Centre for Economic Policy Research, April 2002. Reprinted in Monetary and Fiscal Policies in EMU: Interactions and Coordination, edited by Marco Buti, pp. 29-56. Cambridge, MA: Cambridge University Press, 2003.

Von Hagen, Jurgen, and Barry Eichengreen. (1996). "Federalism, Fiscal Restraints, and 
European Monetary Union." American Economic Review 86, 134-138. 